\title{
CONF-9010292--1
}

\section{OPTICAL DETERMINATION OF THE OXYGEN STOICHIOMETRY OF NANOPHASE METAL-OXIDE MATERIAIS*}

\author{
J. C. Parker** and R. W. Siegel \\ Argonne National Laboratory, Materials Science Division \\ Argonne, Il 60439 \\ **Nanophase Technologies Corporation \\ 1801 Maple Ave., Evanston, II 60201
}

CONF-9010292--1

DE9 1006364

October 1990

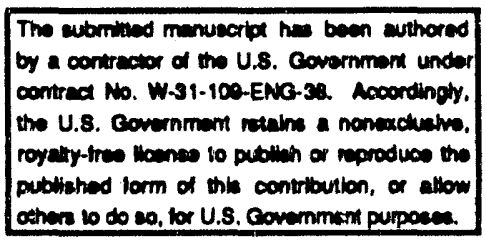

DISCLAIMER

\begin{abstract}
This report was prepared as an account of work sponsored by an agency of the United States Government. Neither the United States Government nor any agency thereof, nor any of their employees, makes any warranty, express or implied, or assumes any legal liability or responsijility for the accuracy, completeness, or usefuiness of any information, apparatus, product, or process disclused, or represents that its use would not infringe privately owned rights. Reference herein to any specific commercial pioduct, process, or service by trade name, trademark, manufacturer, or otherwise does not necessarily constitute or imply its endorsement, recommendation, or favoring by the United States Government or any igency thereof. The views and opiniors of authors expressed herein do not necessarily state or reflect those of the United States Government or any agency thereof.
\end{abstract}

INVITED PAPER submitted for publication in the Proceedings of the Acta Metallurgica Conference on "Materials with Ultrafine Microstructures", Atlantic City, New Jersey, October 1-5, 1990.

*Work supported by the U. S. Department of Energy, BES-Materials Sciences, under Contract W-31-109-Eng-38.

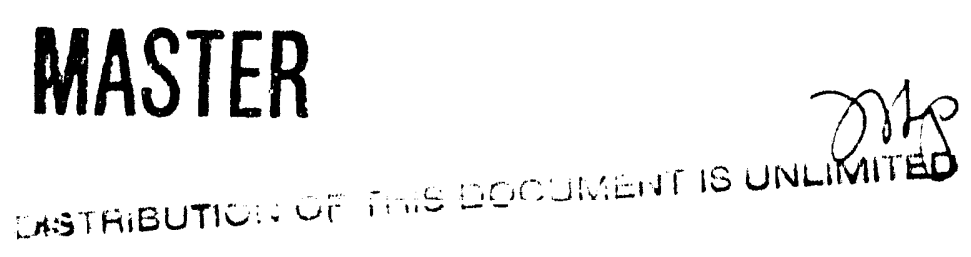




\title{
OPTICAL DETERMINATION OF THE OXYGEN STOICHIOMETRY OF
} NANOPHASE METAL-OXIDE MATERIALS

\author{
J. C. Parker* and R. W. Siegel \\ Argonne National Laboratory, Materials Science Division \\ 9700 South Cass Avenue, Argonne, Dlinois 60439 USA \\ *Nanophase Technologies Corporation \\ 1801 Maple Avenue, Evanston, ㅍ 60201
}

\section{Introduction}

Nanophase metal-oxide ceramics have gained considerable notoriety 1,2 as a consequence of their interesting and potentially useful physical and chemical properties. In the case of nanophase $\mathrm{TiO}_{2}$, with grain sizes in the range $2-20 \mathrm{~nm}$, ductility, enhanced sinterability 3,4 , extensive plastic deformation ${ }^{5}$, and high atomic diffusivities ${ }^{6,7}$ have all been observed in these cluster consolidated materials. These unique or enhanced properties of cluster-assembled $\mathrm{TiO}_{2}$ and other nanophase metal-oxides can be used in a host of applications in current and future commercial technology. However, in order for these materials to be commercially viable, their synthesis must be controlled and highly reproducible. In the case of gas-phase condensed clusters, the synthesis of a metal-oxide is achieved by first creating metal clusters which are subsequently oxidized in an oxygen gas atmosphere or by sublimation of an oxide precursor to form metal-oxide clusters directly $6,8,9$. Although the clusters are highly reactive, due to the large percentage of surface atoms, complete oxidation of the material during cluster synthesis is often incomplete. There are also some cases where the resulting material phase can be adjusted by the rate at which oxidation takes place 6 . Although there are a variety of characterization techniques being used to study nanophase materials, none of these techniques has demonstrated a strong sensititvy to the oxygen stoichiometry.

Quite often the physical properties of metal-oxide ceramics are highly dependent on the metal/oxygen ratio and stoichiometry, and slight deviations can have substantial effects. For example, it has been observed that the mechanical wear characteristics ${ }^{10}$ and electrical and optical properties ${ }^{11}$ of $\mathrm{TiO}_{2}$ can be significantly affected by deviations in the oxygen stoichiometry. To achieve a high degree of reproducibility of nanophase metal-oxides, it is of the utmost importance that identification of the material stoichiometry be made by a simple, nondestructive measurement.

In this paper we present an overview and assessment of the use of optical techniques, primarily Raman scattering, for analyzing the composition a ${ }^{*}$ " stoichiometry of nanophase metal-oxide ceramics. Raman scattering has been shown to be a useful technique for evaluating the oxygen stoichiometry of some metal oxide materials ${ }^{12-14}$. However, it is essential for nanophase materials that grain size effects are considered since their ultrafine grain sizes can produce large shifting and broadening of the Raman spectrum ${ }^{15,16}$.

\section{Experimental}

The nanophase metal-oxide ceramic samples used in this study were produced by the gasphase condensation technique which is described in elsewhere,9. For this study, $\mathrm{TiO}_{2}$ and $\mathrm{ZnO}$ samples were prepared, but for each case the precursor materials and method were quite different. $\mathrm{TiO}_{2}$ samples were made by evaporation of Ti metal in a helium atmosphere, followed by a subsequent rapid oxidation of the metal clusters thus produced. The $\mathrm{ZnO}$ samples were 
made by subliming $\mathrm{ZnO}$ powder in a helium atmosphere ( $\mathrm{ZnO}$ has a low melting temperature and high vapor pressure), However, during sublimation the $\mathrm{ZnO}$ clusters became oxygen deficient and needed to be further oxidized in subsequent oxidation steps. The collected clusters were consolidated into a disk-shaped compact under vacuum (ca. 10-6 $\mathrm{Pa}$ ). The as-consolidated compacts were $9 \mathrm{~mm}$ diameter by ca. $0.2-0.4 \mathrm{~mm}$ thick and contained grains of about $12 \mathrm{~nm}$ average diameter in the case of $\mathrm{TiO}_{2}$ and $5-6 \mathrm{~nm}$ in the case of $\mathrm{ZnO}$. The Raman spectra of the nanophase metal oxide samples were obtained with a Jobin-Yvon, U-1000 Raman spectrometer and a Coherent Innova $70 \mathrm{Ar}^{+}$ion laser operating at $514.5 \mathrm{~nm}$. Further details are described elsewhere ${ }^{13 .}$

\section{Results and Discussion}

In the gas-phase condensation process, as presently exercised, the rapid backfill of oxygen gas into the processing chamber to oxidize the clusters does not usually result in complete oxidation, even in the case of $\mathrm{ZnO}$ powder which starts out stoichiometric and later becomes oxygen deficient after sublimation. In order to achieve complete oxidation of the clusters to a fully stoichiometric value, a post oxidation process is needed whereby the lightly compacted clusters are heated in an $\mathrm{O}_{2}$ atmosphere 6,15 . The process is time consuming and a quantitative assesment of the stoichiometry of the sample during oxidation is not easily obtainable.

Figure 1a shows the Raman spectrum of an as-consolidated nanophase $\mathrm{TiO}_{2}$ sample which had no other processing other than the initial oxidation via a rapid backfill of $\mathrm{O}_{2}$ and consolidation. As can be seen, the spectrum exhibits four distinctive peaks and a broad underlying continuum which tails off at higher Raman shifts. The peaks at $610 \mathrm{~cm}^{-1}$ and 220 $\mathrm{cm}^{-1}$ are attributed to the rutile phase of $\mathrm{TiO}_{2}$ and the peaks at $154 \mathrm{~cm}^{-1}$ and $424 \mathrm{~cm}^{-1}$ are attributed, respectively, to the anatase and rutile phases of $\mathrm{TiO}_{2}$, although they are broadended and shifted relative to the peaks of bulk $\mathrm{TiO}_{2}$ material 12,16 . The Raman spectrum of a fully oxidized sample (annealed in air at $600^{\circ} \mathrm{C}$ ) is shown in Figure 1(b) and exhibits much sharper spectral features and has peak positions that are in excellent agreement with bulk $\mathrm{TiO}_{2}$ material. It is worthwhile to note that even to the naked eye it is obvious that the as-consolidated material is oxygen deficient since it has a black or "gun-metal" blue color, as opposed to a fully oxidized sample which is white.

Previous experimental Raman scattering results on metal-oxide ceramics have shown ${ }^{12}$. 14 that peak shifting and broadening can be related to an oxygen deficiency in the material. However, in the case of ranophase materials, the shifting and broadening of the spectral peaks may, in principie, also be due to grain size effects since it has been shown ${ }^{16}$ in studies on laserinduced crystallization of amorphous silicon that grain size effects (in the $1.100 \mathrm{~nm}$ range) produce similar shifting and broadening. X-ray diffraction and TEM measurements on the $\mathrm{TiO}_{2}$ sample shown in Figure 1 indicate that some grain growth does occur with the oxidation step (the $12 \mathrm{~nm}$ grain size in the as-compacted sample increases to ca. $20 \mathrm{~nm}$ after oxidizing for $1 \mathrm{~h}$ at $600^{\circ} \mathrm{C}$ ); however, the spectral shifting is much larger than that witnessed for the grain size effects seen in nanocrystalline silicon ${ }^{16}$.

Although some grain growth does nccur during oxidatic.. (ca. a factor of 2), a grain size dependence of the Raman spectrum can be ruled out based on two experimental observations ${ }^{13}$ which are exhibited by the peak pcistion versus annealing temperature data shown in Figure 2. First, no spectral charges are observed when the samples are annealed at $200^{\circ}, 400^{\circ}$ and $600^{\circ} \mathrm{C}$ in $\operatorname{ar} \mathrm{Ar}$ atmosphere where some grain growth will be expected ${ }^{3}$ at $600^{\circ}$. As can be seen, spectral changes take place during anriealing in an oxygen atmosphere. Second, an oxygen 
reduction of the fully oxidized samples (achieved by annealing them at $600^{\circ} \mathrm{C}$ in a dynamic $10^{-4}$ $\mathrm{Pa}$ vacuum) shifts the spectrum back toward that of the as-consolidated state, as can be seen by the filled square symbol in Figure 2 which represents the data for the vacuum reduced sample. The grain size would not be expected to shrink upon oxygen reduction. Both of these experiments clearly 'ule out grain size effects and are consistent with earlier Rarnan results 17 on nanophase $\mathrm{TiO}_{2}$ which attribute the grain-size independent line broadening to intragrain defects.

From the experimental evidence discussed above, it becomes apparent that the relationship between the nanophase $\mathrm{TiO}_{2}$ (really $\mathrm{TiO}_{\mathrm{x}}$ ) oxygen stoichiometry and the Raman spectral features can be determined. This was done by progressively measuring the oxygen intake (weight gain) of an as-consolidated sample usirg a TGA microbalance (during cycles at temperatures in the range $300^{\circ}-650^{\circ} \mathrm{C}$ in an $\mathrm{O}_{2}$ atmosphere) and measuring the corresponding Raman spectrum (peak position and broadening) ${ }^{14}$.

The calibration curves plotted in Figure 3 show the peak position of the rutile $447 \mathrm{~cm}^{-1}$ vibrational mode and the peak position and full width at half maximum (FWHM) of the anatase $143 \mathrm{~cm}^{-1}$ vibrational mode, all as a function of the material's O/Ti ratio. The calibration of the Raman spectrum of nanophase $\mathrm{TiO}_{2}$ as a function of $\mathrm{O} / \mathrm{Ti}$ ratio clearly demonstrates that the oxygen stoichiometry can be quantitatively and nondestructively assessed by Raman scattering.

Concurrent with the changes in the peak positions of the Raman spectrum, large changes were observed in the sample's optical properties and Raman scattering intensity during the oxidation. The as-consolidated samples typically have a dark blue color due to defect structures that contribute to a large absorption background ${ }^{11}$. Upon oxidation, the samples lighten to a pale blue color and the intensity of the Raman scattered light increases. At an O/Ti ratio of 1.99 , the samples develop a pale yellow color which progressively changes to white as oxidation continues to 2.0. However, in this same region the Raman spectrum (peak positions and scattered light intensity) changes very little. It is not unusual that the intensity of the Raman scattered light changes as the optical properties of the material change, since the scattering cross section is dependent on the material's optical constants ${ }^{18}$. However, the fact that the optical properties change more visibly than the Raman spectrum for O/Ti ratios greater than 1.99 suggests that a quantiative assessment of the optical constants might be a more sensitive probe of the O/Ti ratio in this range.

To dersonstrate that the sensitivity of the Raman scattering technique is ubiquitous to other Ramain active, nanophase metal-oxides, the Raman spectra of nanophase $\mathrm{ZnO}$ were measured at three stages, (i) as-consolidated, (ii) partially oxidized, and (iii) fully oxiciized and are shown in Figure $4 \mathrm{a}, \mathrm{b}$, and c, respectively. The evolution of the spectra with oxidation shows a change in relative intensity of the $438 \mathrm{~cm}^{-1}$ mode relative to the structure between 515 $530 \mathrm{~cm}^{-1}$. Unlike $\mathrm{TiO}_{2}$, there is little peak shifting, however, calibration of the oxidation state as a function of relative intensity can be made in a manner similar to that performed in Ref. 12. Much like the $\mathrm{TiO}_{2}$ samples, the $\mathrm{ZnO}$ sample color change with oxidation is quite similar, again indicating that optical constant measurements may also be an effective means of characterizing the samples.

\section{Conclusions}

We have demonstrated that the oxygen stoichiometry of nanophase metal-oxide materials can be measured using optical techniques, primarily via Raman scattering. Although a quantitative assessment was made for only the Raman data, optical constants measurements 
(i.e., complex refractive index) can also be employed. The Raman technique, however, has two very distinct advantages over optical constant measurements: (i) Raman scattering is not highly sensitive to surface roughness, and (ii) the Raman microprobe (discussed in Ref. 12) can be employed to examine microscopic sample areas as small as $1 \mathrm{~mm}$ in diameter.

This work was supported by The U.S. Department of Energy, BES-Materials Sciences, under Contract W-31-109-Eng-38. Special Thanks to B. Kestel for his assitance with the annealing experiments. 


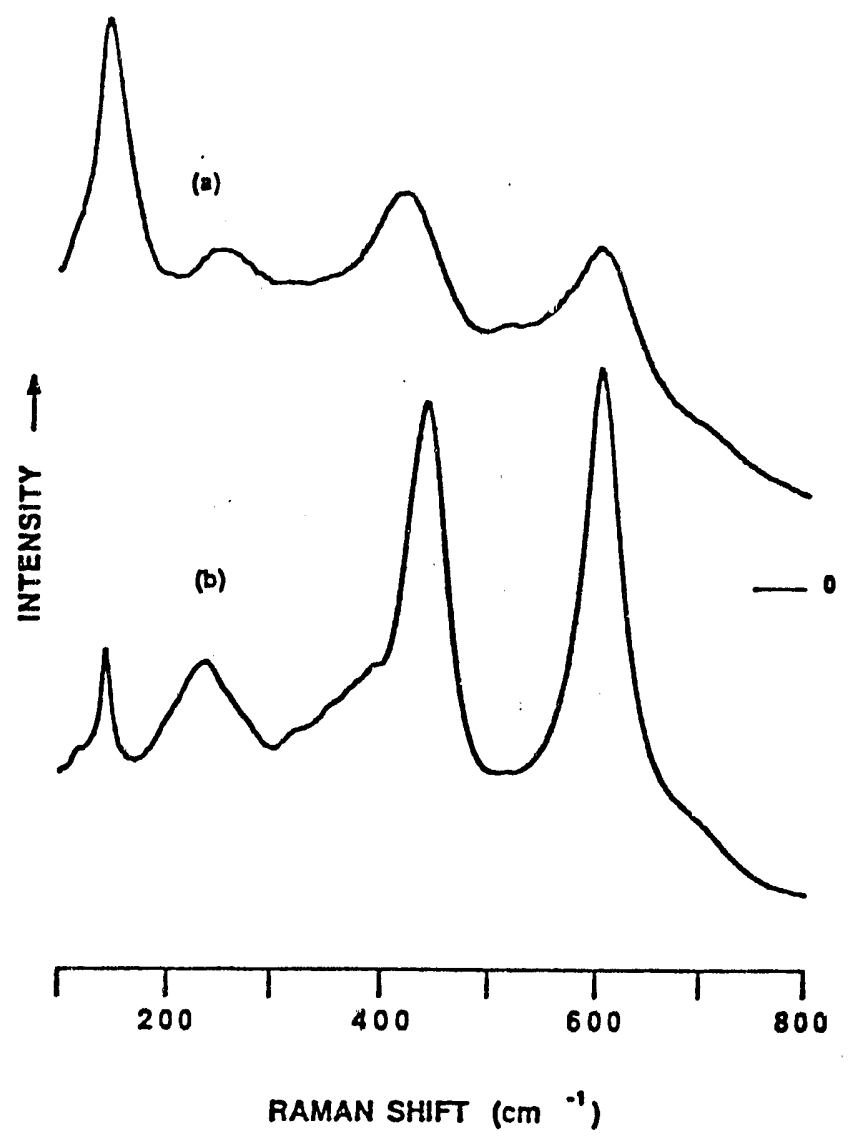

Figure 1. The Raman spectra of nanophase $\mathrm{TiO}_{2}$ in the (a) as-compacted state and (b) the fully oxidized state.

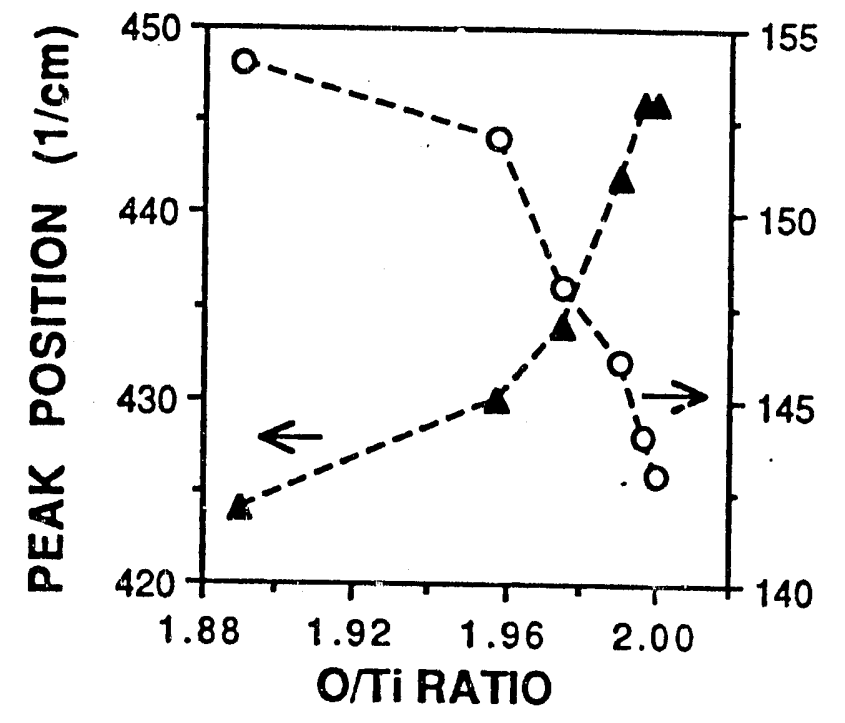

Figure 3. The variation with $\mathrm{O} / \mathrm{Ti}$ ratio of the peak position of (a) the rutile mode and $(b)$ the strongest anatase mode.

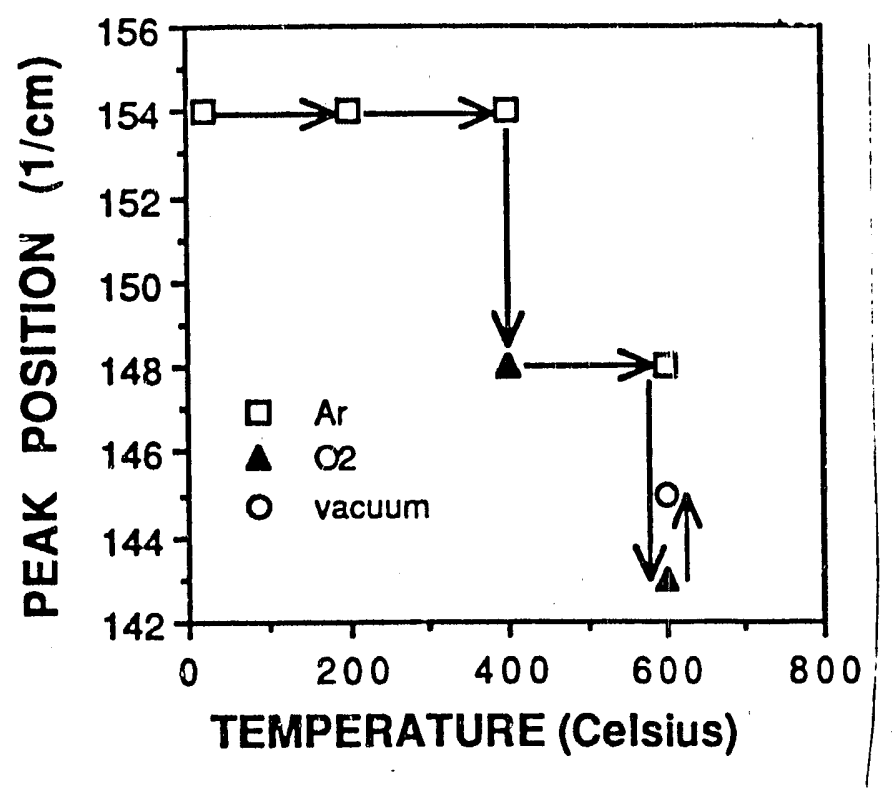

Figure 2. The peak position of the anatase "144 $\mathrm{cm}^{-1 "}$ as a function of annealing temperature in various atmospheres. The arrows indicate the sample history.

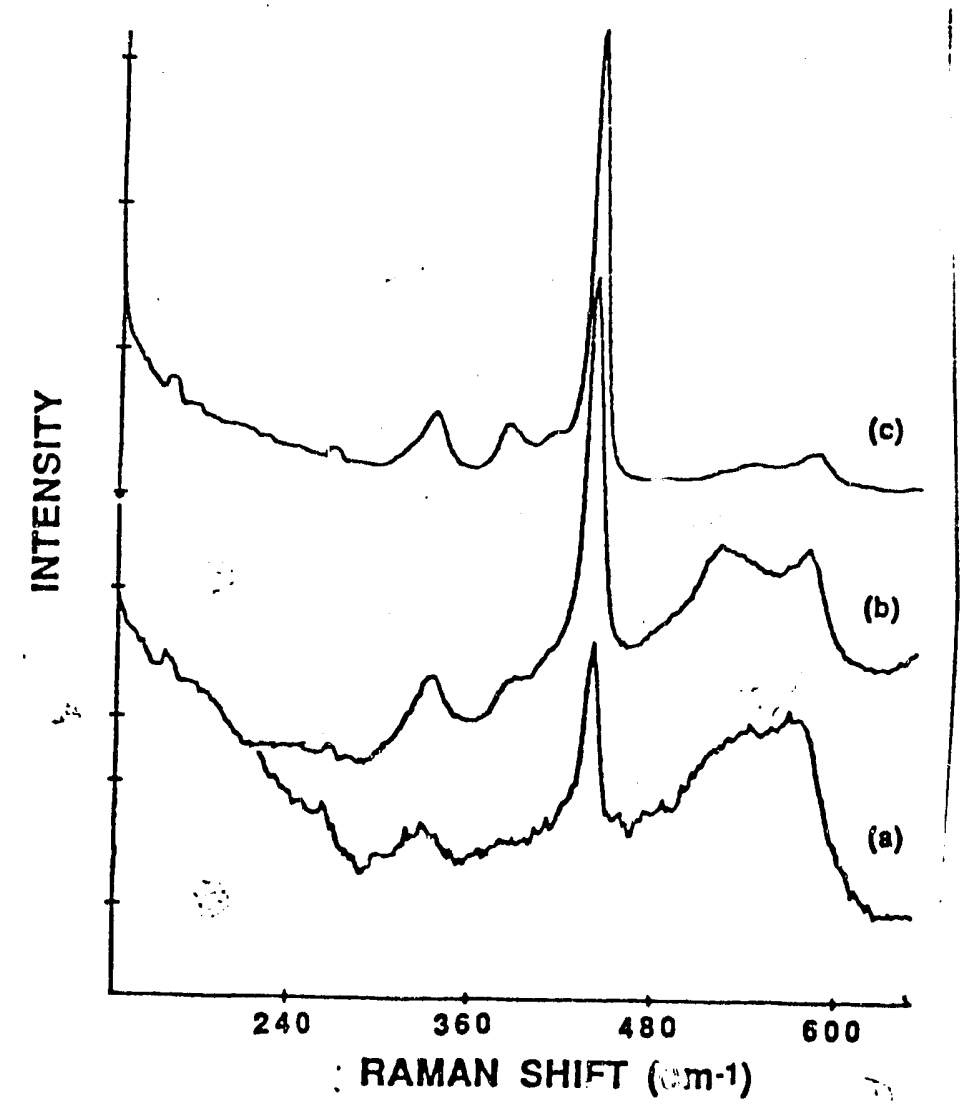

Figure 4. The Raman spectrum of nanophase $\mathrm{ZnO}$ in three stages (a) as-consolidated,

(b) partially oxidized, and (c) fully oxidized. 


\section{References}

1. R. P. Andres, R. S. Averback, W. L. Brown, L. E. Brus, W. A. Goddard,II, A. Kaldor, S. G. Louie, M. Moskovits, P. S. Peercy, S. J. Riley, R. W. Siegel, F. Spaepen, and Y. Wang, J. Mater. Res. 4, 704 (1989).

2. B. H. Kear, L. E. Cross, J. E. Keem, R. W. Siegel, F. Spaepen, K. C. Taylor, E. L. Thomas, and K-N. Tu, Research Opportunities for Materials with Ultrafine Microstructures, NMA3-454 (National Academy Press, Washington, DC, 1989).

3. R. W. Siegel, S. Ramasamy, H. Hahn, Z. Li, T. Lu, and R. Gronsky, J. Mater. Res. 3, 1367 (1988).

4. M.J. Mayo, R.W. Siegel, A. Narayanasamy, W.D. Nix, J. Mat. Res. 5, 1073 (1990).

5. J.L. Logas, H.J. Hofler, H. Hahn, and R.S. Averback, Mat. Res. Soc. Symp. Proc. 196 (1990)

6. J. A. Eastman, Y. X. Liao, A. Narayanasamy, and R. W. Siegel, Mater. Res. Soc. Symp. Proc. 155, 255 (1989).

7. R. S. Averback, H. Hahn, H. J. Höfler, J. L. Logas, and T. C. Shen, Mater. Res. Soc. Symp. Proc. 153, 3 (1989).

8. H. Hahn, J.A.. Eastman, and R.W. Siegel, Cer. Trans. 1B, 1115 (1988).

9. R. W. Siegel and J. A. Eastman, Mater. Res. Soc. Symp. Proc. 132, 3 (1989).

10. M.N. Gardos, Mater. Res. Soc. Symp. Proc. 140, 325 (1989).

11. R. G. Breckenridge and W. R. Hossler, Phys. Rev. 91, 793 (1953).

12. B.C. Cornilsen, E.F. Funkenbusch, C.P. Clarke, P. Singh, and V. Lorprayoon, Mater. Sci. Res. 15, 239 (1983).

13. J.C. Parker and R.W. Siegel, J. Mater. Res. 5, 1246 (1990).

14. J.C. Parker and R.W. Siegel, Appl. Phys. Lett. 57, 943 (1990).

15. I. H. Campbell and P. M. Fauchet, Solid State Commun. 58, 739 (1986), and H. Richter, Z. P. Wang, and L. Ley, Solid State Commun. 39, 625 (1981).

16. H. S. Mavi, A. K. Shukla, S. C. Abbi, and K. P. Jain, J. Appl. Phys. 66, 5322 (1989).

17. C. A. Melendres, A. Narayanasamy, V. A. Maroni, and R.W. Siegel, J. Mater. Res. 4, 1246 (1989).

18. W. Hayes and R. Loudon, The Scattering of Light by Crystals (John Wiley, New York, 1978). 

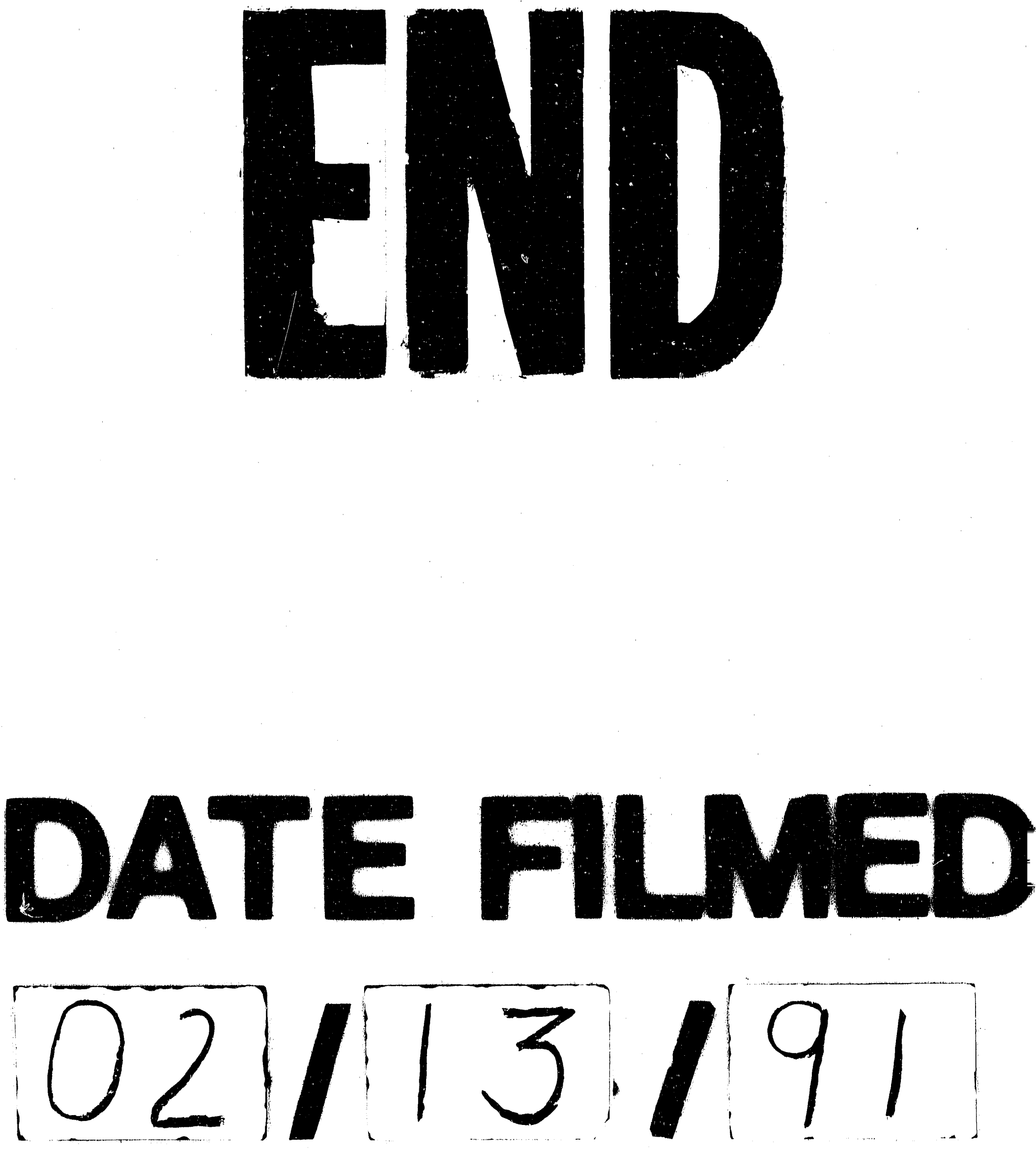
